\title{
The Sexual Behaviour of Panstrongylus megistus (Hemiptera: Reduviidae): an Experimental Study
}

\section{Herton Helder Rocha Pires/*/+ , Marcelo Gustavo Lorenzo, Claudio Ricardo Lazzari**, Liléia Diotaiuti, Gabriel Manrique**}

\begin{abstract}
Laboratório de Triatomíneos e Epidemiologia da Doença de Chagas, Centro de Pesquisas René Rachou-Fiocruz, Av. Augusto de Lima 1715, 30190-002 Belo Horizonte, MG, Brasil *Laboratório de Parasitologia, Departamento de Ciências Básicas da Saúde, Faculdades Federais Integradas de Diamantina, Diamantina, MG, Brasil **Departamento de Biodiversidad y Biología Experimental, Facultad de Ciencias Exactas y Naturales, Universidad de Buenos Aires, Buenos Aires, Argentina
\end{abstract}

The factors affecting the sexual behaviour of Panstrongylus megistus were studied under laboratory conditions. A general description of mating behaviour is presented for this species. The effect of the time elapsed after the first imaginal feeding on the mating frequency, the motivation of males to mate and the rejection behaviour by females, were analyzed. We also determined the number of copulas accepted by females of this species. Finally, the possible existence of a sexual chemical signal promoting male aggregation around mating couples was evaluated. Results showed that mating frequency increased with the time elapsed since the first adult meal. Despite the number of male copulatory attempts did not change as a function of time, the rejection behaviour of females became gradually less frequent. Females rejected mating by means of body flattening on the substrate, abdominal movements, evasion or stridulation. After a single copula, females did not usually accept to mate again. Neither male nor female aggregation around mating couples was observed, suggesting the absence of a sexual assembling pheromone in $\mathrm{P}$. megistus.

Key words: Panstrongylus megistus - Triatominae - sexual behaviour - mating - sex pheromones - Chagas disease

Panstrongylus megistus (Burmeister, 1835) is a bloodsucking bug that is currently considered the main vector of Chagas disease in Brazil, with exception to the Northeastern region. It is a primarily wild species of triatomine bug capable of invading artificial ecotopes and establishing important colonies inside human dwellings. Its control is extremely relevant to avoid the vectorial transmission of the disease, as up to date vaccines against the infection or effective treatments for the chronic stage are not yet available. In endemic areas, wild specimens invade the rural houses continuously, but specially in the humidity period of the year (Dias \& Dias 1968, Dias \& Garcia 1978). Therefore, behavioural studies are extremely relevant in order to allow a better understanding of the mechanisms supporting the orientation and communication of these insects, two crucial processes for successful colonization of novel habitats.

The mating behaviour of several triatomine species has been the subject of diverse studies (Lima et al. 1986 a,b, Rojas et al. 1990, Rojas \& Cruz López 1992, Manrique \& Lazzari 1994). In all cases, it was described as a sequence of definite steps performed by the male. Nevertheless, except for Triatoma infestans (Klüg, 1834), the

Financial support: UNDP/WHO Special Programme for Research and Training in Tropical Diseases, and Capes/Antorchas, Capes/Setcit, Conicet, Fiocruz, and Universidad de Buenos Aires ${ }^{+}$Corresponding author. Fax: +55-31-3295.3115. E.mail: tim@cpqrr.fiocruz.br

Received 9 July 2003

Aceepted 23 March 2004 relevance of the behaviour of females in mating success has been relatively neglected (Lima 1985, Rojas et al. 1990, Rojas \& Cruz López 1992, Manrique \& Lazzari 1994). Unlike many other insect species, triatomine bugs do not perform a stereotyped courtship behaviour in order to attract their partners (Lima 1985).

After two individuals of different sexes encounter, pairing and insemination, by means of spermatophore transference, normally occur. Following mating with a single male, a female will have enough spermatozoa in her spermathecae to fertilise the eggs to be laid along its whole life. Lima (1985) observed that the fertility of eggs laid by P. megistus females who had copulated once was lower than the fertility of those of females that had undertook more than one copula. Lima (1985) also observed that the former females laid unfertilized eggs, even though a similar total number of eggs was produced.

After sexual maturation, insects need to find a partner for mating. It is possible that a sex pheromone with a potential role in the orientation/recognition of individuals of either sex is present in some triatomines (Antich 1965, Neves \& Paulini 1981), although this is a subject that needs further investigations.

Several authors suggested that, during mating, chemical substances are released by one or both members of the couple that lead to the assembling of males around the couple (Baldwin et al. 1971, Manrique \& Lazzari 1995). Baldwin et al. (1971) suggested that such substances may also have an "aphrodisiac" effect on Rhodnius prolixus (Stäl, 1859) males, as several mating attempts between individuals of this sex were observed by the authors. Manrique and Lazzari (1995) have suggested that the aggregation of males around mating couples would be associated to polyandry in $T$. infestans. 
The aim of the present work was to make a general description of mating behaviour in P. megistus and to analyse experimentally the factors affecting it. Finally, we tested whether males of this species aggregate around mating couples in this context, as it was described for $T$. infestans and $R$. prolixus.

\section{MATERIALS AND METHODS}

Insects - Fifth instar nymphs of $P$. megistus were sorted by sex, fed and kept apart in acrylic recipients with a piece of filter paper as substrate, until their imaginal ecdysis. Insects were reared at $25 \pm 2^{\circ} \mathrm{C} ; 65 \% \mathrm{RH}$ and fed on mice (Mus musculus).

The mating behaviour of P. megistus - A male and a female were placed in a circular glass arena $(10 \mathrm{~cm}$ height x $25 \mathrm{~cm}$ diameter) with a piece of filter paper as substrate. Data were gathered from the observation of 10 different pairs (room temperature: $25 \pm 1{ }^{\circ} \mathrm{C} ; 53 \pm 3 \% \mathrm{RH}$; illumination intensity: 35 lux).

Feeding and mating motivation - The maturing of the sexual behaviour of males and females of this species and the occurrence of the copula were analyzed using virgin couples $(\mathrm{N}=20)$. The time elapsed between the first and last imaginal moult of the group of insects used did not exceed 20 days. Adults were fed ad libitum only once approximately 10 days after their ecdysis. Assays were started one day after feeding, repeated every one day at the same daytime, i.e., 15:00 h, and lasted for 15 days. A single male and a single female were placed in a circular experimental arena $(10 \mathrm{~cm}$ height $\mathrm{x} 15 \mathrm{~cm}$ diameter $)$ and the behaviour of the couple was studied by direct observation during $10 \mathrm{~min}$. The onset of copulation was prevented carefully by using a brush just before of its start, in order to keep the insects virgin along the whole experiment. We quantified for each experimental day: (a) the number of copulatory attempts by males; (b) the number of rejections performed by females; and (c) the number of "copulas" (given that the insects did not actually copulate, we considered that a potential "copula" took place when the male and female made contact between their genitalia). Assays were performed at $25 \pm 2{ }^{\circ} \mathrm{C}, 65 \% \mathrm{RH}$, and under a controlled illumination intensity of 20 lux.

Mating frequency - In order to check the usual frequency and number of copulas performed by females of this species, 17 virgin couples, 20 days old, were individually placed for a period of $1 \mathrm{~h}$ in the circular arena. Each pair was submitted to the same procedure every week, throughout two months. The assays were carried out at $25 \pm 2{ }^{\circ} \mathrm{C} ; 65 \% \mathrm{RH}$, and under controlled illumination intensity of 20 lux. For the insects used in this experiment, feeding was provided once a week on thionembutal anaesthetised mice.

Assembling around mating couples - This experiment was designed to test whether males of this species aggregate in the presence of a mating pair, as other triatomines do. Thirty days old virgin adults, starved for 7 days were used. Assays were performed in the circular arena and under controlled environmental conditions $\left(25 \pm 1^{\circ} \mathrm{C}, 53 \pm\right.$ $3 \%$ RH, 35 lux). Four experimental series were conducted and in all series insects were always released in the center of the arena. In the first and second series, 4 males were initially released and, after $10 \mathrm{~min}$, a single female (1st series) or a marked male (2nd series) was added to the group. In the 3rd and 4th series, 4 females were released and after $10 \mathrm{~min}$, either a male (3rd series) or a marked female (4th series) was added. Each assay was recorded using a video recorder along $1 \mathrm{~h}$ and the behaviour of the insects posteriorly analyzed. The distance between each insect in the arena relative to the last individual released was measured every $1 \mathrm{~min}$ of the assay in all experimental series. With these distance data, an aggregation index was computed. In this way, the spatial distribution of these insects was quantified by measuring the change in the distance to the reference individual as a function of time, before, during, and after the copula. The aggregation of the insects was analyzed recording their position $1 \mathrm{~min}$ before the start of the copula and subsequently, every 1 min until the copulating pair started to walk around.

Statistical analysis - The effect of the time elapsed since the first adult meal on the mating motivation of insects was analyzed by means of ANOVA. Regression analysis was applied to describe the relation between posfeeding time and the tendency to reject males by females, and also to describe the temporal change in mating frequency. ANOVA was performed to test the tendency of $P$. megistus males to aggregate around mating couples as a function of the time after the occurrence of copulation.

\section{RESULTS}

The mating behaviour of P. megistus - In all cases, the physical contact between individuals began by initiative of the male, which jumped or climbed over the female and grabbed it with its legs. After holding her with his legs, the male mounted the female and then tilted laterally to allow the approximation of its genitalia to that of the female. Afterwards, it placed the end of its abdomen below that of the female and it exposed its genitalia. With the aid of its paramers, the male secured the genitalia of the female, allowing the introduction of its copulatory organ. The copula lasted an averaged of $21 \mathrm{~min}$ and $4 \mathrm{~s}$ (range 17 $\min 14 \mathrm{~s}-25 \min 55 \mathrm{~s}$ ) and could be divided into two phases: the 1st started with the juxtaposition of the genitalia and lasted up to the moment when the male released the female's body, remaining united only through the genitalia, and secondly, from this moment up to the complete separation of the insects. The $1 \mathrm{st}$ phase averaged $15 \mathrm{~min}$ and $9 \mathrm{~s}$ (range $13 \mathrm{~min}-20 \mathrm{~min} 10 \mathrm{~s}$ ), and the 2 nd one about $5 \mathrm{~min}$ and $5 \mathrm{~s}$ (range $46 \mathrm{~s}-11 \mathrm{~min}$ and $11 \mathrm{~s}$ ). At this second phase, the female generally walks, pulling the male around.

We found that the female determines the occurrence of a copula, given that it could be receptive or non-receptive to the mating attempts performed by males as it was observed in other triatomines (Manrique \& Lazzari 1994). If non-receptive, it could refuse the male through different behaviours.

We were able to characterize and quantify the occurrence of 4 kinds of rejection behaviours performed by females, i.e., body flattening: the female flattens the ventral part of its body against the substrate in order to avoid the male to position itself laterally with respect to it (39.3\%); abdominal movements: the female shakes her body up and down, getting the male off it (29.3\%); evasion: the 
female escapes walking avoiding physical contact with the male (15\%), and stridulation: the female rubs the end of the proboscis against the prosternal stridulatory groove to produce a vibratory signal $(16.4 \%)$, rejecting in this way the male copulatory attempts.

Feeding and mating motivation - The number of mating attempts displayed by the 20 males (mean $=7,7 \pm 0,9$ s.e.) did not vary according to the time elapsed since feeding. On the other hand, the proportion of males rejected by females significantly decreased with time (ANOVA, $p$ $=0.005 ;$ Fig. 1 ). As a consequence, a significant increase in the mating frequency with increasing post-feeding time was observed (ANOVA $p=0.001$; Fig. 2). The daily percentage of copulating couples varied from around $10 \%$ during the first days after feeding to ca. $40 \%$ around day 12. Besides, according to our observations $75 \%$ of the experimental pairs expressed their motivation to copulate at least once along the 15 days of observation.

Mating frequency - We observed that $76.5 \%$ of the couples copulated, throughout a 2 month interval. In most cases the females of $P$. megistus performed only one copula. Indeed, only a single couple of 17 accomplished a second

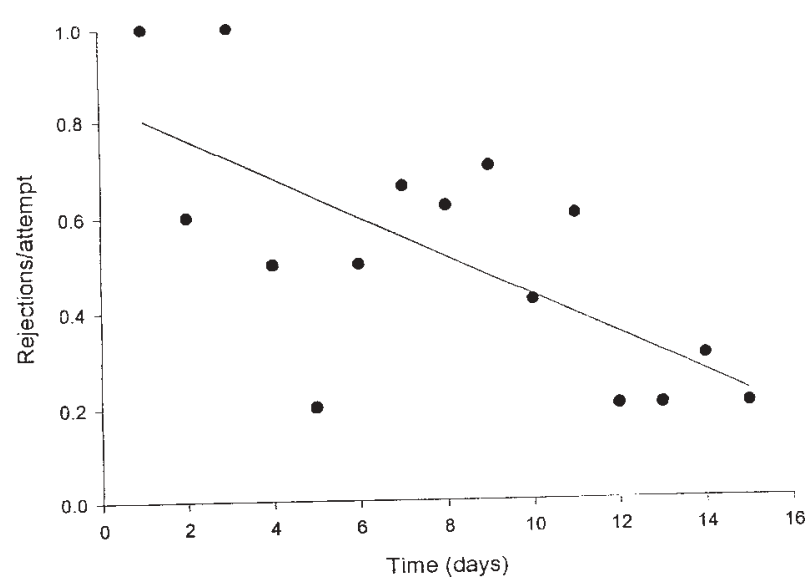

Fig. 1: proportion of sexual rejections per male copulatory attempt by females of Panstrongylus megistus as a function of post-feeding time (ANOVA, $\mathrm{p}=0,005, \mathrm{~N}=108$ )

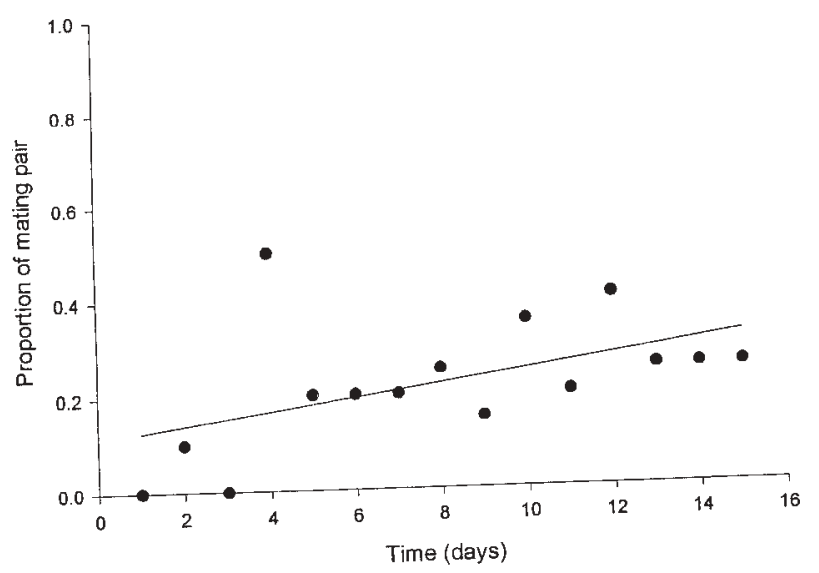

Fig. 2: proportion of copulating pairs of Panstrongylus megistus as a function of post-feeding time. The regression line represents the variation of mating frequency as a function of time (ANOVA, p = $0.001, \mathrm{~N}=55$ ) mating. The lack of a second copula was due to the rejection behaviour of the female, as most attempts from males for a second copula resulted in rejections.

Assembling around mating couples - Results from the first series of assays, i.e., when 4 males and one female were released in the arena, showed that the distance from the other males to a mating couple did not change with time after the copula began (ANOVA for repeated measures, N.S.; Fig. 3a). The same was observed when the spatial distribution of females was quantified in presence of a copulating pair, i.e. 4 females and one male (ANOVA with repeated measures, N.S.; Fig. 3b). When only males were tested, the distance between the insects did not vary along time (second series, ANOVA with repeated measures, N.S.; Fig. 3c). However, in the 4th series, females showed a significant variation in their spatial distribution in absence of copula, i.e., they aggregated after some minutes (ANOVA with repeated measures, $\mathrm{p}=0.007, \mathrm{~F}=2,55$ df $=14$; Fig. 3d).

Although no assembling around mating couples was observed for any sex, males performed 65 unsuccessful attempts to copulate for a second time. On the other hand, $100 \%$ of mated females rejected subsequent mating attempts from the males, at least during the 10 min of assay following the copula (first series).

\section{DISCUSSION}

The sequence of behavioural steps that lead to mating in $P$. megistus follows the general model described by Lima et al. (1986b) in this species. Males of $P$. megistus are the sex that actively performs the approximation of the couple, as in all triatomines studied to date.

Manrique and Lazzari (1994) studying T. infestans, observed that these insects do not remain joined through their genitalia after the copula, but separate immediately after the male descends from the female. This behaviour allows the occurrence of successive copulas, aided by the fact that couples of this species apparently emit a pheromone that promotes the aggregation of males around the copulating pair. According to Manrique and Lazzari (1995), this polyandric behaviour may promote a higher genetic variability in the off-springs in T. infestans. This would be particularly relevant when new colonies are founded by dispersing females (Schofield 1985). Contrarily, remaining bound through the genitalia after the first copula could represent a mechanism to prevent new copulatory attempts by other males, maybe increasing the reproductive success of the first male (Schöfl \& Taborsky 2002). Looking for differences in reproductive success of males in polyandric triatomines like $T$. infestans or $R$. prolixus using genetic markers may help to determine if sperm competition or other mechanism enhancing reproductive success is present in these insects. Pires et al. (2002) utilised a recessive character for red eye colour in T. infestans to analyse the fertility and fecundity of these insects. When a first copulating male is recessive, i.e., it has red eyes, and a second copula happens with a wild type male, these authors observed that the sperm that fertilises the eggs is gradually substituted, as the number of offsprings from the red eye male gradually declines. The contrary was not observed, as once a female copu- 


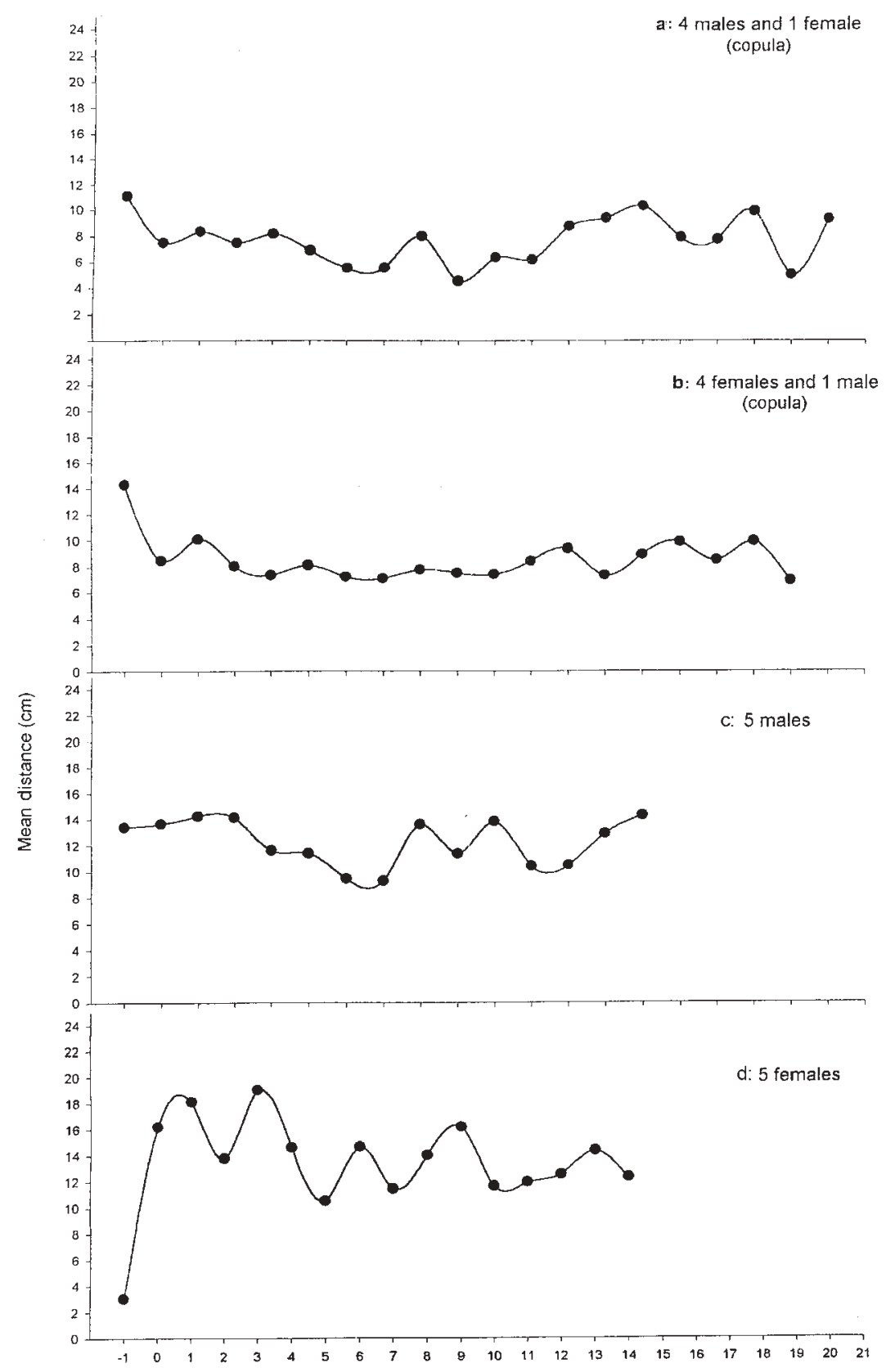

Fig. 3a: mean distance \pm standard error of the distance of four males to a female in the arena as a function of time (ANOVA with repeated measures N.S., $\mathrm{N}=5$ ). Time 0 correspond to the initiation of mating; - $\mathrm{b}$ : mean distance \pm standard error of the distance of four females to a male in the arena as a function of time (ANOVA with repeated measures N.S., $N=5$ ). Time 0 correspond to the initiation of mating; - c: mean distance \pm standard error of the distance of four males to a marked male in the arena as a function of time (ANOVA with repeated measures N.S., $\mathrm{N}=5$ ). Time 0 was settled by computing the mean time interval elapsed between the introduction of the copulating male or female and mating in the mating series; - $\mathrm{d}$ : mean distance \pm standard error of the distance of four females to a marked female in the arena as a function of time (ANOVA with repeated measures $\mathrm{p}=0,007, \mathrm{~N}=5$ ). Time 0 was settled by computing the mean time interval elapsed between the introduction of the copulating male or female and mating in the mating series.

lated with a male of the wild type, posterior copulas with recessive males did not derive in a gradual substitution of fertilising sperm. These results lead those authors to suggest a potential sperm competition mechanism in that species.

Previous studies with P. megistus have mentioned the occurrence of rejection behaviour displayed by females of this species, but without describing the different mo- dalities of this behaviour (Lima et al. 1986a). Here, we were able to distinguish four kinds of rejection behaviours, resembling those previously described for $T$. infestans (Manrique \& Lazzari 1994), i.e., stridulation, abdominal movements, escape, and body flattening over a substrate. In $P$. megistus, flattening was the most frequent kind of rejection behaviour, showing a similar proportion of occurrence for both species; i.e., $39.3 \%$ for $P$. megistus and \pm 
$40 \%$ for T. infestans. Stridulation in triatomines has been considered by several authors, either as a sexually related behaviour or as a defense response (Moore 1961, Manrique \& Lazzari 1994, Roces \& Manrique 1996, Manrique \& Schilman 2000, Schilman et al. 2001). According to Manrique and Lazzari (1994), non-receptive T. infestans females stridulate spontaneously, in order to reject the male copulatory attempts. Roces and Manrique (1996) and Manrique and Schilman (2000) studying the stridulation of $T$. infestans and $R$. prolixus respectively, suggested that the relevant signal is a substrate borne vibration. In addition, they found differences in the frequency and temporal pattern of the signals produced by the same individual in different contexts, i.e., rejecting a male or after mechanical disturbance. In the present work, we report the occurrence of female stridulation, as a male-deterring signal in $P$. megistus. A comparative analysis would reveal whether this species is also able to produce different signals at different contexts.

Several reports described an important role for the age of the males in the occurrence of the first mating in triatomines (Regis et al. 1985, Malo et al. 1993). Under our experimental conditions, the number of copulatory attempts by the males did not vary along time, i.e., they always exhibited the same motivation to copulate. The results presented in those reports are not totally comparable to ours due to the differences in the age and treatment of the insects. We observed that the main factor conditioning mating was the disposition of females to mate, expressed as their rejection behaviour. P. megistus females seem to change their disposition to copulate depending on their nutritional conditions, as already demonstrated for T. infestans by Manrique and Lazzari (1994).

The probability to reject mating attempts of males by females decreases with increasing time after the first adult meal. It is clear that the rejection behaviour of females conditions the success of the copula in P. megistus as it was previously described for T. infestans (Manrique \& Lazzari 1994).

Our results show that the frequency of the copula depended on the post-feeding conditions of adult bugs. Initially after feeding, the lowest mating frequencies observed were probably due to the rejection behaviour of females. Our conclusions are based upon considering the post-feeding conditions of the experimental insects as the cause of the changes observed in the behaviour of the females. We can not exclude that the modifications observed are the simple consequence of their age, and not the effect of feeding on maturation. Regis et al. (1985) reported that adult $T$. infestans females began to copulate with an imaginal age of just four days. Nevertheless, they did not analyse their behaviour, in order to establish the proneness of young females to copulate.

Manrique and Lazzari (1994) working with T. infestans described that 16 days after feeding approximately $100 \%$ of the pairs expressed their motivation to copulate daily. Differently, our results with $P$. megistus reached a maximum daily level of $40 \%$ copulating pairs only after 12 days post-feeding, percentage which resembles results obtained by Lima et al. (1986b). This lower daily motivation to copulate does not necessarily reflect that the insects are imma- ture, as approximately $75 \%$ of the pairs expressed their motivation to copulate at least once at the end of this experiment. It is possible that the experimental design described by Manrique and Lazzari (1994), who worked with T. infestans, would require adjustments, e.g., time to perform assays, in order to use it with $P$. megistus comparatively. The low number of pairs that copulated both in this experiment and in that evaluating the mating frequency in a 2 month follow up, i.e., 75 and 76,5\%, indicate the need of more data to better understand the sexual behaviour of this species.

Borba (1972) observed that $P$. megistus females that had copulated avoided new male attempts. In the present work, this particular behaviour was also observed and quantified; indeed, mated females rejected subsequent attempts to copulate.

Several authors have remarked that after a single mating, P. megistus females would be able to produce fertile eggs along their entire life (Neiva 1914, Pinto 1930, Lima 1940, Pessoa \& Martins 1982). Lima (1940) observed that $P$. megistus females copulate just once, but also reported that under some situations a second copula occurs. Here, only one couple over 17 performed a second mating (5.9\%). Nevertheless, in other cases, the characteristic behavioural steps preceeding mating were observed, but the genitalia of the insects never became joined. On the contrary, Lima (1985) observed that $P$. megistus females are able to copulate up to seven times during their life, showing a mean of $2.6 \pm 1.6$ copulas per female. However, these differences could be due to the distinct experimental lapses, two months vs entire life.

Our observation of an aggregation of females in the absence of a mating couple probably occurred due to the spontaneous tendency of these bugs to maintain an intense body contact with the substrate and conspecifics, i.e., thigmotaxis. Surprisingly this behaviour was not found in our experiments with males in the absence of mating couples. Besides, our results did not reveal the existence of male aggregation around mating couples for P. megistus. This suggests that a sex aggregation pheromone is absent in this species. This is quite consistent with the fact that $P$. megistus females seem not to perform successive copulas. Thus, male recruitment around the mating couple would not be relevant, as in polyandric triatomine females (Manrique \& Lazzari 1995).

Our work reveals that mating in P. megistus would follow a different behavioural pattern when compared with other triatomines studied to date. Females of this species seem to perform just a single or few copulas during their imaginal life, a fact that agrees with the post-copulatory behaviour observed and with the absence of male-assembling signals in the sexual context of this species. Both, behavioural and ecological work will be conducted, in order to comprehend the reasons and adaptive value of these dissimilar reproductive strategies in this group of insect vectors.

\section{REFERENCES}

Antich AV 1965. Introducción al estudio de la atracción por el olor en reduvideos hematófagos transmisores de la enfermedad de Chagas. Investigaciones de laboratorio con 
el Triatoma phyllosoma pallidipennis (Stal). Arch Venez,Med Trop Parasitol Med 51: 329-344.

Baldwin WF, Knight AG, Lynn KR 1971. A sex pheromone in the insect Rhodnius prolixus (Hemiptera: Reduviidae). Can Entomol 103: 18-22.

Borba AM 1972. Biologia de Panstrongylus megistus (Burmeister, 1835) em Condições Artificiais - Aspectos Ecológicos e Epidemiológicos desta espécie no Estado do Paraná (Hemiptera, Reduviidae, Triatominae), MSc Thesis, $100 \mathrm{pp}$.

Dias E, Dias JCP 1968. Variações mensais da incidência das formas evolutivas do Triatoma infestans e do Panstrongylus megistus no município de Bambuí, Estado de Minas Gerais. Mem Inst Oswaldo Cruz 66: 209-226.

Dias JCP, Garcia ALR 1978. Vigilância epidemiológica con participación comunitaria en un programa de enfermedad de Chagas. Bol Of Sanit Panam 81: 533-544.

Lima AC 1940. Insetos do Brasil. Rio de Janeiro. Esc Nac Agronomia 2: 167-171.

Lima MM 1985. Aspectos do Comportamento Reprodutivo de Panstrongylus megistus (Burmeister, 1835) (Hemiptera: Reduviidae) sob Condições de Laboratório, MCs Thesis, Instituto Oswaldo Cruz, Rio de Janeiro, 108 pp.

Lima MM, Jurberg P, Almeida JR 1986a. Behaviour of triatomines (Hemiptera: Reduviidae) vectors of Chagas' disease. I - Courtship and copulation of Panstrongylus megistus (Burm., 1835) in the laboratory. Mem Inst Oswaldo Cruz 81: 1-5.

Lima MM, Jurberg P, Almeida JR 1986b. Behaviour of triatomines (Hemiptera: reduviidae) vectors of Chagas' disease. II - Influence of feeding, lighting and time of day on the number of matings, mating speed and duration of copulation of Panstrongylus megistus (Burm. 1835) under laboratory conditions. Mem Inst Oswaldo Cruz 81: 381-388.

Malo EA, Ramírez-Rovelo A, Cruz López L, Rojas JC 1993. Life cycle and influence of age and feeding on the first mating of Triatoma mazzottii (Hemiptera: Reduviidae). Mem Inst Oswaldo Cruz 88: 203-206.

Manrique G, Lazzari CR 1994. Sexual behaviour and stridulation during mating in Triatoma infestans (Hemiptera: Reduviidae). Mem Inst Oswaldo Cruz 89: 629-633.

Manrique G, Lazzari CR 1995. Existence of a sex pheromone in Triatoma infestans (Hemiptera: Reduviidae): I - Behavioural evidence. Mem Inst Oswaldo Cruz, 90: 645-648.

Manrique G, Schilman PE 2000. Two different vibratory sig- nals in Rhodnius prolixus (Hemiptera: Reduviidae). Acta Trop 77: 271-278.

Moore TE 1961. Audiospectrographic analysis of sounds of Hemiptera and Homoptera. Ann Entomol Soc Am 54: 273291.

Neiva A 1914. Revisão do Gênero Triatoma laporte, Tese de livre docência na cadeira de História Natural Médica e Parasitologia, Faculdade de Medicina do Rio de Janeiro, 80 pp.

Neves DP, Paulini E 1981. Atração sexual em Panstrongylus megistus e Triatoma infestans (Hemiptera, Reduviidae) por feromônio. Rev Bras Entomol 25: 301-306.

Pessoa SB, Martins AV 1982. Parasitologia Médica, $11^{\mathrm{a}}$ ed., Guanabara Koogan, Rio de Janeiro, 872 pp.

Pinto C 1930. Tratado de Parasitologia, Vol. IV: Artrópodes Parasitos e Transmissores de Doenças (Tomo I) - Isosídeos e Outros, Cap. III - Triatomíneos. Bibliot Scient Bras, Rio de Janeiro, p. 173-234.

Pires HHR, Abrão DO, Machado EMM, Schofield CJ, Diotaiuti L 2002. Eye colour as a genetic marker for fertility and fecundity of Triatoma infestans (Klug, 1834) Hemiptera, Reduviidae, Triatominae. Mem Inst Oswaldo Cruz 97: 675678.

Regis L, Gomes YM, Furtado AF 1985. Factors influencing male accessory gland activity and first mating in Triatoma infestans and Panstrongylus megistus (Hemiptera: Reduviidae). Inst Sci Applic 6: 579-583.

Roces F, Manrique G 1996. Different stridulatory vibrations during sexual behaviour and disturbance in the blood-sucking bug Triatoma infestans (Hemiptera: Reduviidae). J Insect Physiol 42: 231-238.

Rojas JC, Cruz López L 1992. Sexual behaviour in two species of Tritoma plyllosoma complex (Hemiptera; Reduviidae) under laboratory conditions. J Med Entomol 29: 13-18.

Rojas JC, Malo EA, Gutierrez-Martinez A, Ondarza RA 1990. Mating behaviour of Triatoma mazzottii Usinger (Hemiptera: Reduviidae) under laboratory conditions. Ann Entomol Soc Am 83: 598-602.

Schilman PE, Lazzari CR, Manrique G 2001. Comparison of disturbance stridulations in five species of triatomine bugs. Acta Trop 79: 171-178.

Schofield CJ 1985. Population dynamics and control of Triatoma infestans. Ann Soc Belg Med Trop 65: 149-164.

Schöfl G, Taborsky M 2002. Prolonged tandem formation in firebugs (Pyrrhocoris apterus) serves mate-guarding. Behav Ecol Sociobiol 52: 426-433. 